\title{
XR-TECAN Teaching Model for Chinese Traditional Art Education
}

\author{
Min Gao \\ Taiyuan University of Science and Technology, \\ Taiyuan 030024, Shanxi, China
}

\begin{abstract}
Chinese traditional art education plays a unique role in transmitting traditional culture and in developing social civilization but is limited by the monotony of the teaching model structure, its inflexibility in learning time and space, constraints in the teaching scale, and lack of immersive experience. This article discusses the application of extended reality $(X R)$ technology to the seven links of Chinese traditional art education, namely introduction, evaluation, analysis, practice, adjustment, appraisal and research, initiating a new human-machine interactive virtual reality teaching model, known as the XR-TECAN teaching model for Chinese traditional art education. This new teaching model covers basic technology, the equipment environment, content resources, application implementation and the digital cloud. Compared with the old apprenticeship model in traditional art education, the XR-TECAN teaching model is a breakthrough that allows learners to freely switch between virtual reality and the real world in a deeply immersive experience that improves education efficacy.
\end{abstract}

Science Insights Education Frontiers 2021; 10(1):1365-1380.

Doi: 10.15354/sief.21.or057

How to Cite: Gao, M. (2021). XR-TECAN: A teaching model for Chinese traditional art education. Science Insights Education Frontiers, 10(1):1365-1380.

Keywords: Extended Reality (XR), China, Traditional Art Education, XR-TECAN Model, Teaching Model 


\section{The Status Quo of Chinese Traditional Art Education}

\section{The Roles of Chinese Traditional Art Education}

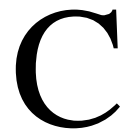

HINESE traditional art, an essential part of Chinese traditional culture, is rich in Chinese ideology and art spirit. Chinese traditional art education keeps Chinese traditional culture alive and helps build values for social norms and education in three ways. First, Chinese traditional art education plays an important part in aesthetic education by cultivating a student's aesthetic taste and judgement through the perception, appreciation and expression of beauty. Second, Chinese traditional art education functions as a moral educator. Among Six Arts put forward by Confucius in Spring and Autumn Period, Music (also called dance accompanied by music) represents art, ranking just second to Ritual (representing etiquettes, laws, ethics). Rituals and Music are important instructive tools for civilizing an individual's nature, both extrinsic (ritual) and intrinsic (music). Rituals promote mutual respect, while Music encourages mutual love. Ritual helps people differentiate from one another while $\mathrm{Mu}$ sic reminds them of their common identity (Xue, 2010). Ritual and Music, complement each other, working together to develop civilization in society. Third, Chinese traditional art education helps nurture multiple skills. Research highlights six groups of skills as compelling qualifications for 21st century talents: 1) critical thinking and problem-solving; 2) innovation, creativity and entrepreneurship; 3) self-directed learning; 4) communication; 5) collaboration and leadership; and 6) global citizenship and character (Ontario Ministry of Education, 2016; Sinay \& Ryan, 2016; Rifandi \& Rahmi, 2019). Activities in art education, such as artistic perception, appreciation and creation, can develop a learner's observation, imagination, exploration, assertion, understanding, expression, creation, and cooperation abilities.

\section{Problems with Chinese Traditional Art Education}

While maintaining the function of artistic education in the new age, Chinese traditional art education faces the problem of an outdated teaching mode that no longer suits current demand, in terms of teaching mode, human resources, curriculum design, teaching environment and teaching scale.

Correspondence to: Min Gao, Taiyuan University of Science and Technology, Taiyuan 030024, Shanxi, China. Email: thebestminmin@126.com

Conflict of Interests: None.

(C) 2021 Insights Publisher. All rights reserved.

Creative Commons Non Commercial CC BY-NC: This article is distributed under the terms of the Creative Commons Attribution-NonCommercial 4.0 License (http://www.creativecommons.org/licenses/by$\mathrm{nc} / 4.0 /$ ) which permits non-commercial use, reproduction and distribution of the work without further permission provided the original work is attributed by the Insights Publisher. 
The Chinese traditional art teaching model was historically one of intergenerational transmission ( $\mathrm{Lu} \& \mathrm{Liu}, 2019$ ), master-apprentice transmission, old-type opera school training (Liang, 2009), or master's class-basically dominated by the thousandsyear-old apprenticeship system. For the past hundred years, class teaching methods have been accepted in Chinese traditional art education, yet the traditional teaching methods characterized by apprenticeship and teaching by precept and example, remains, showing resilience despite experiencing difficulty in the transformation to class teaching (Gu, 2019). Methodologically, oral inspirational teaching is the most basic mode of an apprenticeship system, whereby teachers impart skills by enlightening while students learning by being enlightened. 'Being enlightened' is the key here and refers to knowing, understanding, and awakening. By 'being enlightened,' students fully comprehend the implication and spirit of Chinese traditional art. However, this methodology is experiencing increasing challenges in its attempts to offer deep understanding and full awakening, because teaching vehicles are undergoing tremendous change. In historical times, when the life pace was slow and information communication was sluggish, teachers and students lived together and language bore special advantages as an effective tool. Currently, in the context of convenient information sharing, rich on-site artistic experience, reduced face-to-face interaction between teachers and students, knowledge iteration and the widening generation gap, the traditional oral inspirational teaching method is less attractive. Without the desirable teaching effectiveness, it fails to meet high teaching standards regarding teacher performance and profound communication. In terms of teaching human resources, oral inspirational teaching requires teachers of an exceptional artistic level and the current scarcity in qualified teachers results in instability in teaching quality (Tian \& Wang, 2021). Also, disparity in teaching levels leads to difficulties building a standard curriculum structure, which hinders popularization of traditional art education. Furthermore, traditional face-to-face teaching needs a relatively fixed time and space, preventing students from learning anytime and anywhere, rendering the traditional teaching process impossible at modern-day scales. Thus, face-to-face teaching sets limits to the scale of traditional art education.

In the past two years, the covid-19 pandemic has necessitated distance teaching and led oral inspirational teaching to be discarded. Superficially, this demonstrates the inadaptability of this traditional teaching mode to the current educational context. Yet, more essentially, it reflects the discordant relationship among performers in education (teachers and students), educational content and educational media (language, teaching materials, environment). A compelling need exists for a new teaching model, by which traditional art can be easily learned by anybody, at anytime and anywhere. The development of new teaching interactive media to build teaching situations where both teachers and students are deeply immersed in the process of artistic appreciation and experience is required to enhance the appeal of artistic beauty, while reducing the cost of 'being inspired' and 'being enlightened' and increasing teaching efficacy. Extended reality $(\mathrm{XR})$ technology makes this possible. 


\section{Implications and Value of XR in Chinese Traditional Art Education}

\section{Connotation of Extended Reality}

Extended reality (XR) is an umbrella term covering virtual reality (VR), augmented reality (AR), mixed reality (MR) and other newly developed immersive technologies (Fan, Hou, Zhang \& Liao, 2021). XR experiences encompass the major technological phases of VR, AR and MR and integration of the three. Table 1 compares the four technologies in terms of concept, feature, device, field of application and educational implications.

\section{Implications and Value of the XR Teaching Model for Chinese Traditional Art}

By connecting, mapping and augmenting the real and virtual worlds, XR technology creates human-machine interactive virtual reality teaching situations that enable users to be deeply immersed in an environment that seamlessly switches between the virtual and real worlds. Functional improvement and application expansion are enriching and developing the content of XR technology. By integrating new technologies such as artificial intelligence, mass data, holographic projection and 3D printing, XR can break the limitations on teaching time, space and scale, and realize self-adaptive teaching in which repeated evaluations can be made on teaching-learning interactions.

Built on XR technology, the new teaching model for Chinese traditional art will make existing teaching methods more effective, initiate innovations and exhibit several advantages as outlined below.

\section{Immersive Situational Presentations}

Available applications and innovative research in XR technology contribute to life-like presentations for teaching. In the multiple sensory virtual reality, students can move fluidly among different time and space settings appropriate to different art teaching content. The virtual classroom is created to be almost real, a real-life version of "The Magic School Bus.” (Hopkins \& Lillard, 2021) Improved iterations of leading technology provide technical support for such possibilities. For example, the light field display project Starline, unveiled by Google in May 2021 demonstrates the promise of such technologies: 'One of the proudest things is that once you sit down and start talking, the technology will disappear in the background, and you can focus on the most important thing: the person in front of you (actually a 1:1 high simulation virtual portrait that is difficult to be identified by the naked eyes).' (Liu, 2020, May 19) Eventually, XR holographic projection technology and naked eye 3D imaging technology will be possible, allowing the virtual image to be directly projected into real three-dimensional space as a 


\section{Table 1. Comparisons among VR, AR, MR, and AR.}

\begin{tabular}{|c|c|c|c|c|c|}
\hline Items & Concept & Feature & $\begin{array}{l}\text { Terminal } \\
\text { Device }\end{array}$ & $\begin{array}{l}\text { Application } \\
\text { Field }\end{array}$ & $\begin{array}{l}\text { Educational } \\
\text { Implication }\end{array}$ \\
\hline VR & $\begin{array}{l}\text { A computer simulation } \\
\text { system that can create } \\
\text { and experience virtual } \\
\text { world. It integrates } \\
\text { multi-source infor- } \\
\text { mation, simulates } \\
\text { entity behaviors and } \\
\text { presents three- } \\
\text { dimensional dynamic } \\
\text { scenes }\end{array}$ & $\begin{array}{l}\text { Virtual scene } \\
\text { simulating reality }\end{array}$ & $\begin{array}{l}\text { VR head } \\
\text { display, VR } \\
\text { wearable } \\
\text { device, } \\
\text { PC terminal }\end{array}$ & $\begin{array}{l}\text { Game, film and } \\
\text { television, tourism, } \\
\text { education, tele- } \\
\text { medicine }\end{array}$ & \multirow{3}{*}{$\begin{array}{l}\text { 1. Increase the } \\
\text { understanding } \\
\text { of spatial struc- } \\
\text { ture and func- } \\
\text { tion } \\
\text { 2. Learn Lan- } \\
\text { guage Associa- } \\
\text { tion } \\
\text { 3. Keep long } \\
\text { term memory } \\
\text { retention } \\
\text { 4. Improve the } \\
\text { effectiveness of } \\
\text { physical opera- } \\
\text { tion } \\
5 . \text { Improve } \\
\text { learning motiva- } \\
\text { tion and partici- } \\
\text { pation }\end{array}$} \\
\hline $\mathrm{AR}$ & $\begin{array}{l}\text { A technology that } \\
\text { calculates the image } \\
\text { position and angle in } \\
\text { real time and adds the } \\
\text { corresponding image. } \\
\text { lt sets the virtual world } \\
\text { in the real world on the } \\
\text { screen and interacts } \\
\text { with it. }\end{array}$ & $\begin{array}{l}\text { Superposition of } \\
\text { virtual scene and } \\
\text { real world }\end{array}$ & $\begin{array}{l}\text { AR head } \\
\text { display, AR } \\
\text { wearable } \\
\text { device, ex- } \\
\text { ternal device, } \\
\text { PC terminal }\end{array}$ & $\begin{array}{l}\text { 3D street view, } \\
\text { education, securi- } \\
\text { ty, industry, tour- } \\
\text { ism, aviation, } \\
\text { medicine }\end{array}$ & \\
\hline$\overline{M R}$ & $\begin{array}{l}\text { By introducing real } \\
\text { scene information into } \\
\text { the virtual environ- } \\
\text { ment, mixed reality } \\
\text { technology sets up an } \\
\text { interactive feedback } \\
\text { information loop be- } \\
\text { tween the virtual } \\
\text { world, the real world } \\
\text { and users, so as to } \\
\text { enhance users' sense } \\
\text { of reality. }\end{array}$ & $\begin{array}{l}\text { Enhanced ver- } \\
\text { sion of AR, com- } \\
\text { bination of VR } \\
\text { and AR, richer } \\
\text { than VR with a } \\
\text { wider perspective } \\
\text { than AR technol- } \\
\text { ogy }\end{array}$ & $\begin{array}{l}\text { Interactive } \\
\text { wearable } \\
\text { 6DOF inside- } \\
\text { out integrated } \\
\text { device, } \\
\text { iphone } \\
\text { handheld SR } \\
\text { device, PC } \\
\text { terminal }\end{array}$ & $\begin{array}{l}\text { Game, design, } \\
\text { sports, film and } \\
\text { television, social } \\
\text { networking, re- } \\
\text { mote cooperation, } \\
\text { scenario aware Al } \\
\text { role generation }\end{array}$ & \\
\hline XR & $\begin{array}{l}\text { Extended reality en- } \\
\text { compasses virtual } \\
\text { reality, augmented } \\
\text { reality, mixed reality } \\
\text { and other immersive } \\
\text { technologies. It is an } \\
\text { interactive technology } \\
\text { between reality and } \\
\text { virtual system, and } \\
\text { between information } \\
\text { and media. }\end{array}$ & $\begin{array}{l}\text { Natural Interac- } \\
\text { tion, } \\
\text { Light-weight } \\
\text { equipment, } \\
\text { Sensory immer- } \\
\text { sion, } \\
\text { Negligible tech- } \\
\text { nical traces, } \\
\text { direct immersion } \\
\text { in personalized } \\
\text { situational expe- } \\
\text { rience }\end{array}$ & $\begin{array}{l}\text { Mobile } \\
\text { phone, head } \\
\text { display, PC } \\
\text { terminal, all- } \\
\text { in-one ma- } \\
\text { chine, XR } \\
\text { screen }\end{array}$ & $\begin{array}{l}\text { Commerce, medi- } \\
\text { cal care, military, } \\
\text { industrial manu- } \\
\text { facturing, trans- } \\
\text { portation, tourism, } \\
\text { education }\end{array}$ & $\begin{array}{l}\text { 1. Rich and } \\
\text { attractive learn- } \\
\text { ing experience } \\
\text { 2. New data } \\
\text { analysis and } \\
\text { display extrac- } \\
\text { tion methods } \\
\text { 3. Expanded } \\
\text { knowledge } \\
\text { acquisition } \\
\text { channels } \\
\text { 4. Personalized } \\
\text { services } \\
\text { 5. Reduced } \\
\text { cognitive bur- } \\
\text { den } \\
6 . \text { Free learning }\end{array}$ \\
\hline
\end{tabular}

projected picture that is continuous and undistorted, making it difficult for the naked eye to distinguish the virtual from the real. This extremely realistic way of situational presentation will allow art education to return to its real-life context, enabling learners to perceive and understand the art more intuitively. This situationally immersive teaching mode and teaching narration can solve the problem faced by traditional art educa- 
tion, namely, the monotony of teaching methods, and greatly enrich expressiveness in art teaching.

\section{Comprehensive Artistic Education}

\section{- Resource Integration}

The XR teaching model integrates abundant high-quality resources including practical teaching resources, public digital resources (such as XR art exhibitions, XR concerts, XR drama performances, XR museums, XR master classes, and XR public community art), public entity resources and scientific research resources. It extends teaching resources in multiple dimensions and globalizes resource coverage to tackle problems in art learning, experience and practice that result from a lack of art resources.

\section{- Perception and Understanding}

The new XR teaching model enables learners to perceive and understand teaching content comprehensively through coordinating multiple senses such as sight, hearing, touch, smell and taste. It utilizes artificial intelligence (AI) technology to identify learners, obtain data information in real time, and adjust the self-adaptive teaching module in a timely manner so that learner's perception and understanding of content will better meet their learning level and needs.

\section{- Cross-Disciplinary Comprehensive Teaching}

The new teaching model systematically integrates a variety of artistic resources into the teaching and provides interdisciplinary comprehensive training and development that will improve learning among students with diverse learning abilities and increase the comprehensive artistic literacy of all students.

\section{In-Depth Interactive Experience}

Under the XR teaching model, all artistic activities are closely related to social life, so that 'learning for learning's sake' is avoided and the ideas of 'learning for life' and 'learning is life' are advocated. XR teaching content shortens the distance between educational activities and real life and intensifies the effectiveness, profundity and breadth of the interactive experience.

\section{- Effective Interactive Experience}

As an educational medium, XR technology is fully integrated with teaching elements such as teaching content, teaching performers and teaching links for education and teaching interaction. The XR teaching model is a breakthrough compared to the traditional teaching model characterized by one-way information transmission, with strong communication by teachers and weak feedback by learners. The XR teaching model 
encourages multiple in-depth interactions among people, objects and events. It activates educational elements that traditionally have low efficiency and insufficient interaction and solves the problems of poor communication and unilateral preaching by allowing extensive two-way communications. Moreover, XR combined with AI technology sets collective learning modules and personalized self-adaptive learning modules to meet the different needs of learners. Learners can choose different learning modules according to their learning ability and learning interest, to make the interactive processes more efficient and improve teaching outcomes.

\section{- Profound Emotional Experience}

Under the XR teaching model, a learner's strong sense of substitution, artistic emotion and in-depth experience are stimulated. Gamified teaching can arouse learner's interest, make interactions more entertaining and increase learner participation. In the XR teaching field, the XR teaching content is vivid, the information flow is free and convenient, and the teaching interaction becomes simple and easy. Instead of being the authority of information, teachers act as students' companions in situational experiences, teaching narrative and knowledge construction. This equal relationship further encourages interaction, exchange of feelings and sharing of experience. Neuroscience studies indicates that good virtual reality experiences can effectively improve learner's participation, knowledge memory level and self-efficacy.

\section{- Extensive Learning Experience}

XR technology can present artistic concepts and images that are unimageable and inaccessible in traditional art education, building an interactive experience of full-time knowledge association and learning construction, and providing learners with broad experience and innovative spaces for learning and creation.

\section{Flexible Teaching Environment}

The XR teaching model is characterized by flexibility in time and space, specifically by the free extension of teaching space and time that is possible through the repeatability of the teaching process.

The extension of teaching space in the new teaching model means that venues go far beyond traditional physical classrooms, extending across real physical spaces, public virtual spaces, global digital spaces and into inaccessible space. The XR teaching model, as a bridge from classroom learning to activities outside of school (museums, concert halls, exhibition halls, etc.), integrates internal and external learning modes, and creates close connections between cognition and practice. Teaching space in the form of 'butterfly change fields' will be created through technologies like AI and Internet of xroom (Yang, Zhan, Chen, \& Wang, 2021). The vast and intelligent educational space enables learners to enjoy face-to-face interactions with teachers without leaving home. In addition, under the XR model, educational events can be organized without space 
limitations, such as when watching first-class artistic performances, viewing teaching demonstrations by famous masters and appreciating national artistic customs with regional characteristics.

The extension of teaching time in the XR teaching model meets users' demands for the ability to learn anytime and anywhere. Students will not have to make appointments with teachers or worry about missing scheduled performances or exhibitions. If students can draw relevant teaching resources and public service resources from the digital cloud, they can instantly immerse themselves in vivid learning situations.

Finally, constancy of the teaching process refers to the fact that XR teaching model guarantees a complete record of the whole teaching process through big data technology. Apart from using notes and memory in reviewing and thinking on learned topics, learners can repeat the teaching process as many times as they want.

\section{Expanded Teaching Scale}

After a pre-learning evaluation and construction of the self-adaptive learning module, students can choose between collective teaching modules and personalized learning modules after putting on mixed reality equipment. The same teaching content can provide high-quality teaching services to numerous students without time and space constraints, overcoming the limitations of traditional art teaching in the one-to-one apprenticeship system and greatly expanding the scale of art teaching.

The XR teaching model also standardizes teaching procedures for Chinese traditional art education and reduces teachers' workloads for knowledge sharing and performance demonstration activities, allowing them to divert their energy into other teaching activities such as guiding students to feel, appreciate and create beauty; answering student questions and removing doubts; and motivating students. The simple operation and easy popularization of the XR teaching model alleviates the limitation of scale in traditional art teaching caused by inadequate educational resources.

\section{XR-TECAN Teaching Model for Chinese Traditional Art Education}

Given the potential value of XR technology in Chinese traditional art education, we propose a new model for Chinese traditional art teaching that borrows design concepts and constituent elements from three frameworks: 1) Intelligent Technology Ecological Structure Framework (Yang \& Zhao, 2021), 2) 662-N61 Curriculum Construction Framework (Lyu, 2021) and 3) PSSP Intelligent Learning Space Design Framework (Yang, Ding \&Chen, 2021).

Following the Intelligent Technology Ecological Structure Framework, the new XR model takes the original concepts of 'basic equipment' and 'cloud digital resources,' dividing these into three layers: 'basic technology layer,' 'equipment environment layer' and 'digital cloud layer,' according to function. Next, the 'educational content' and "teaching process" of the original framework are integrated into a 'content resource 
layer' and an 'application implementation layer.' Together, these constitute the five main layers of the new model. The content resource layer contains four elements, XR character Avatars, XR teaching aids and textbooks, XR scene construction and XR resource integration, which together encompass educational performers, teaching contents and educational media.

The application implementation layer is at the core of the new teaching model, applying XR technology to the teaching process and links of Chinese traditional art education. The six teaching links in the 662-n61 Curriculum Construction Framework for vocational education (introduction, analysis, imitation, adjustment, evaluation and research) are modified so that the teaching process of Chinese traditional art education is divided into seven links: introduction, evaluation, analysis, practice, adjustment, appraisal, and research, taking the characteristics of art education into consideration. A "collective teaching module" and "self-adaptive teaching module" are built, and learners choose the appropriate teaching module according to their own needs. The learning modules are updated through digital cloud data and intelligent analysis to make teaching compatible with learning in real time.

The overall framework of the new model is based on the PSSP Intelligent Learning Space Design Framework, and the final XR-TECAN teaching model for Chinese traditional art education is shown in Figure 1.

In the following sections, we elaborate further on the XR-TECAN teaching model for Chinese traditional art education, in terms of technology, equipment, content, application and number.

\section{Technology}

The XR-TECAN teaching model is a conglomerate of multiple technologies, using extended reality as its core technology and integrating holographic projection, 5G networks, multiple perception, 3D printing, $\mathrm{AI}$ and other technologies to achieve connections between virtual and real environments, deep immersion and positive interaction. Holographic projection technology and $5 \mathrm{G}$ provide a technical guarantee for the sensitivity and authenticity of interactive feedback during teaching. With 3D printing technology, the constructed virtual images and created XR art works are materialized, making the real generation of virtual world items a reality. AI makes mutual understanding between people and machines possible, and interaction among people, things, environments and numbers smoother.

\section{Equipment}

In terms of equipment and environmental support, the XR-TECAN teaching model includes four areas. 1) Recognition and tracking of human and field interactions, including image and speech recognition systems, behavior tracking and a tactile feedback system. 2) A sensing system that is the input and output of information transmission. 3) The terminal equipment, including the XR head display, the 3D naked eye screen, holo- 


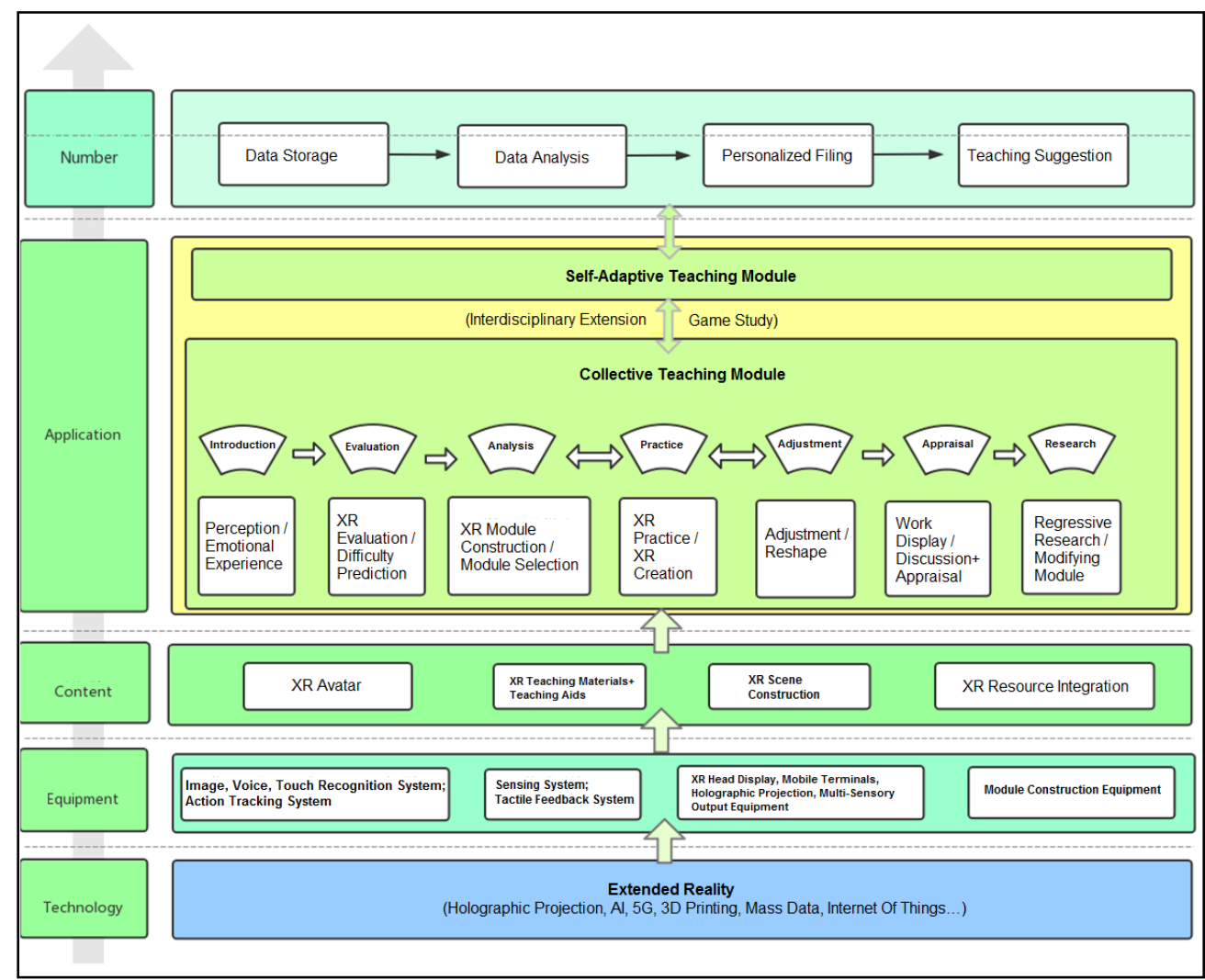

Figure 1. XR-TECAN Teaching Model for Chinese Traditional Art Education

graphic projector, and multi-dimensional output equipment for the effects of smell, taste, touch and sound. 4) Learning module construction equipment, including a $360^{\circ}$ video camera and editing equipment.

\section{Content}

At the content resource layer, the main elements of teaching with XR technology are shaped. First, teachers and learners, as major participants in teaching, can be packaged or reshaped according to the needs of art teaching situations; these are character avatars. For example, XR technology can dress up and beautify the images of teachers and students. Furthermore, processed images can be used to create artistic images for roleplaying. Take Liang Shanbo and Zhu Yingtai as examples. In teaching the drama, teachers and students can not only dress up according to the situation but can also play the characters of Liang Shanbo and Zhu Yingtai, or even become the butterfly after the transformation. Second, XR teaching materials and teaching aids are tailored for the XR teaching model. The materials are no longer text-dominated paper media, but also in- 
clude multi-sensory digital media. Mixed reality teaching materials and teaching aids make virtual images realistic, such as astronomical stars, rare metals, or historical celebrities. Augmented reality teaching materials and teaching aids not only present the teaching content, but also apply the teaching information, such as text, sound and animation, onto the real objects, effectively augmenting and supplementing information. When music is played, XR technology can automatically mark the virtual music score and suggest corrections according to the player's performance to help learners clarify key and difficult points in performance. By projecting different textures and colors onto the surface of real objects, XR technology can display the dynamic development process of relevant objects. For example, the weathering process of stone is demonstrated by projecting dynamic texture onto the stone surface; the image of swinging willow branches is projected onto a working fan, and learners feel the artistic concept of a breeze caressing the willow.

Third, XR scene construction technology can present artistic scenes across time and space according to the needs of art teaching, such as a space journey, underwater travel, trip to ancient times, and joint artistic performances by artists at home and abroad. In addition, XR scene construction technology can be cleverly combined with physical props to create the artistic atmosphere of teaching scenes and teaching narration. For example, when building the virtual scene of Chinese landscape painting, a dry ice machine and water mist machine are used to create the fairyland atmosphere of water mist on the river and clouds on the top of the mountain. Finally, XR resource integration includes digital resource integration and physical resource integration. By connecting with the XR field of public art, a joint mechanism for public art teaching is established. Virtual in-classroom learning and practice can be extended to off-line activities. For example, students first learn singing skills through XR technology, next build a virtual concert scene to simulate a stage practice, and then cooperate with offline live concert venues to participate in physical concert performances. In this way, the transition from theory to practice is made smooth.

\section{Application}

In the XR-TECAN model, traditional art teaching is segmented into seven links.

\section{Introduction}

In Chinese traditional art education, situational experience and artistic perception are the main cognitive sources. Through immersive art scene presentations, learners can intuitively perceive and experience the curriculum material, such as enjoying concerts, visiting art exhibits in museums, and understanding the background era of ancient buildings through ancient scenes.

\section{Evaluation}


With the help of an intelligent evaluation system, the XR-TECAN model will test the learners' artistic interactive experience, evaluate their knowledge level and professional skills, and predict possible learning difficulties in follow-up teachings.

\section{Analysis}

Big data are used to analyze students' learning behavior and interactive activities. Students' learning characteristics and learning styles are studied and judged, matching teaching modules are built and teaching activities are carried out that combine discipline characteristics, training objectives and progress.

\section{Practice}

After completing the preliminary art experience and learning, the XR-TECAN model will create practice and creative situations through XR scene construction and XR resource integration. The XR teaching materials and equipment will then be used to practice and create art. All behavior data will be uploaded to the cloud and a personalized database established.

\section{Adjustment}

After analyzing the practice, the XR-TECAN model will identify the deficiencies and gaps in learning, and learners will return to the teaching module again and conduct a new round of exercises and practice. 'Practice' is the essence of Chinese traditional art teaching. Through comparison, improvement, and adjustment, the three links of 'analysis-practice-adjustment' can be repeated for an unlimited number of times.

\section{Appraisal}

Taking the generation of guidance and suggestions as the purpose for evaluation, the XR-TECAN model appraises assignment presentation, finds the advantages and disadvantages of learning methods according to learners' strengths and weaknesses, and customizes exercises and practical guidance for them.

\section{Research}

Regression, research and analysis are conducted to the whole teaching process.

The whole learning process contains two modules, namely the collective teaching module and the personalized teaching module. Most often, the collective teaching module is adopted in teaching, with extensive interaction, exchange and cooperation between teachers and students. However, each learner can also use a personalized selfadaptive teaching module tailored to their own situation or choose to switch between collective learning and self-adaptive learning.

Game learning and interdisciplinary learning, as two prime characteristics of the new model, penetrate the whole teaching process, making the learning process more 
interesting and attractive, and increasing the opportunity for knowledge application in real life.

\section{Number}

The digital cloud encompasses data storage, intelligent analysis, personalized data and teaching suggestions, providing stable data support and strategy matching to ensure effective operation of the whole teaching process.

The XR-TECAN teaching model is supported and promoted by five layers: technology, equipment, content, application, and number, moving from bottom to top. The name XR-TECAN teaching model is from the initials of the five words in its main structure: T, E, C, A, N with XR- as prefix, which stands for extended reality. This highlights how the five layers of the model are continuously refined and connected with the seven links of teaching, forming an in-depth collaboration with an internal mechanism.

\section{Application of XR-TECAN Teaching Model for Chi- nese Traditional Art Education}

At present, XR technology has been applied in K-12 education, academic setting in colleges and universities, tourism education, art education, vocational education, and entertainment. The XR-TECAN teaching model for Chinese traditional art education is expected to promote revisions in teaching performers, teaching content, teaching media, and interactive methods.

\section{$X R+$ Teaching Performers}

Varying from traditional teaching methods, XR technology not only adds makeup and costuming for teachers and students through augmented reality technology, but also generates a new XR image that fits the needs of the situation through the virtualization and reconstruction of teachers as XR avatars that can simulate human actions and facial expressions. Users can customize the face, hair and clothing of their XR Avatar through the editor (Fan, Hou, Zhang \& Liao, 2021).

\section{$X R+$ Teaching Content}

Compared with traditional teaching, the XR teaching model focuses on teaching situations and narratives, covers a wider range of knowledge and in more dimensions, weakens the barrier caused by discipline boundaries, displays the knowledge connection between multiple disciplines, and presents knowledge that aligns with the realities of life. Through $360^{\circ}$ degree video shooting and editing of XR scenes, video learning modules and courses can be updated in a timely manner. 


\section{$X R+$ Teaching Media}

XR technology is employed not only to reform teaching materials and teaching aids, but also to design an educational environment and to build teaching scenes. XR teaching materials and teaching aids are characterized by a wide presentation field and strong presentation capacity. They present the teaching content through multi-sensory channels such as sight, hearing, smell, taste and touch, or project images skillfully onto physical materials of different properties according to the needs of the situation, to make the knowledge presentation concrete, vivid and interesting. Moreover, the XR education environment layout is a breakthrough to the limits of physical teaching spaces, creating a virtual extension across physical space, public virtual spaces (virtual museum, concert hall, exhibition hall, library, science and technology museum, playground, etc.), global digital space and inaccessible space (outer space, human viscera, deep sea, etc.), so that learners can be in these environments without leaving home. In addition, the construction of educational scenes not only allows free extension in space, but also unlimited time extensions. With the accumulating improvement of an XR resource library, XR scenes will enable free extensions across time and space, allowing simulations of the past and projections of the future.

\section{$X R+$ Interactive Methods}

Interaction is core to any art education activity, connecting the teachers, teaching content and teaching media. Through cognitive experience, teachers and students perceive the high resolution simulated situations created by XR technology from the multisensory dimensions of sight, hearing, smell, touch and taste. Also, XR teaching materials can interpret the process of change that artistic works intend to express (for example, the stone weathering and wind blowing willow branches mentioned above in Section 3). In teacher-student interactions, the huge knowledge base provided by XR can compensate for any teacher insufficiency in interdisciplinary comprehensive knowledge, enabling interdisciplinary comprehensive development of the students. When XR works as media to impart knowledge, teachers can focus on observing and analyzing students' learning behaviors. Technologies like tactile feedback, facial emotion and gesture recognition are used to analyze learners' demands, evaluate teaching behavior, build self-adaptive learning files, and provide personalized teaching guidance. Cognition, practice, experiment and creation in the XR teaching field are performed autonomously and flexibly. Practical creation and physical works can be integrated into XR scenes and the created XR virtual works can be printed in different proportions. Therefore, twoway transmission between virtual and real environments can occur.

\section{Conclusion}

The XR-TECAN teaching model for Chinese traditional art education caters to the learning habits and cognitive traits of modern people, especially the current generation 
of digital natives. It breaks through bottlenecks in art education, such as monotonous teaching methods, limitations in learning time and space, limited education scale, high requirements for teachers and a lack of immersion experience. With this new model, Chinese traditional art teaching can be upgraded from 'integration of environment and body' to 'unity of mind and body.' (Xu, et al, 2021) The XR-TECAN teaching model is expected to help evolve a new ecology where anyone can learn art, at anytime and anywhere, in an interesting and easy way. With the power of new technologies, we anticipate Chinese traditional art education will make greater differences in the digital age than ever before.

Acknowledgement: This work was supported by 2021 teaching reform and innovation project of colleges and universities in Shanxi Province. This article is part of the Research on the Role of Subject Consciousness of College Students in "Ideological and Political Course" and Network Teaching.

\section{References}

Fan, L.Y., Hou, S.M., Zhang, K.F., \& Miao, X.L. (2021). Hot Topic Review of Extended Reality (XR) 2020. Science and Technology Review, 39(1):220-232.

Fan, L.Y., Hou, S.M., Zhang, K.F., \& Miao, X.L. (2021). Hot Topic Review of Extended Reality (XR) 2020. Science and Technology Review, 39(1):220-232.

Gu, P. (2019). The Harm of Widespread Scientism to Art Education. Journal of Nanjing Academy of Art (Arts and Design), 2019(6):144-146+210.

Hopkins, E. J., \& Lillard, A. S. (2021). The Magic School Bus dilemma: How fantasy affects children's learning from stories. Journal of Experimental Child Psychology, 210:105212. DOI: https://doi.org/10.1016/j.jecp.2021.105212

Liang, G.H. (2009). Communication and Education: Research and Analysis on Chinese Traditional Art. Cultural Heritage, 2009(3):1625.

Liu, W.H. (2020, May 19). Google Unveils Breakthrough Light Field Display Project
Starline. Retrieved September 09, 2021, from

https://www.sohu.com/a/467235419_213766

Lu, H.L., Liu, F.S. (2019). Cultural Miracles Created by Ancient Chinese Private University. Media and Art Research, (02):144-155.

Lyu, Z.F. (2021). Construction and Practice of "662-n61" Curriculum System in the Context of "Educational Reform in Three Dimensions". Educational Theory and Practice, 41(21):53-56.

Ontario Ministry of Education. (2016) 21stcentury competencies: Foundation document for discussion. Ontario Public Service.

Rifandi, R., \& Rahmi, Y. L. (2019, October). STEM education to fulfil the 21 st century demand: a literature review. In Journal of Physics: Conference Series (Vol. 1317, No. 1, p. 012208). IOP Publishing. DOI: https://doi.org/10.1088/17426596/1317/1/012208

Sinay, E., \& Ryan, T.G. (2016) Unpacking the Toronto District School Board's Vision for Learning: Research Brief on Global Citizen- 
ship and Character. Toronto, Ontario, Canada: Toronto District School Board.

Tian, H.X., \& Wang, L.E. (2021).The Value Orientation, Problem Manifestation and Optimization Logic of Art Education in Colleges and Universities in China. 2021(4):83-86. DOI:

https://doi.org/10.13236/j.cnki.jshe.2021.04. $\underline{014}$

Xu, R.Y., Chen, W.D., Zheng, S.S., Zhang, Y.F., Yuan, F., Ge, W.S., \& Wei, H.M. (2021). Implication Construction, Realization Mechanism and Educational Application of Immersive Experience -- Also on the New Field of AI + Immersive Learning. Distance Education Journal, 39(1):28-40. DOI: https://doi.org/10.15881/j.cnki.cn33$1304 / g 4.2021 .01 .003$

Xue, Y.W. (2010). Study on Book of Rites \& Book of Music. Beijing: Guangming Daily. ISBN: 9787511207401.
Yang, X.M., \& Zhao, R.B. (2021). Intelligent Technology Ecology Drives Future Education Development. Modern Distance Education Study, 33(2):13-21.

Yang, Y.P., Zhan, L.C., Chen, Z.H., \& Wang, T. (2021). Ecological Construction of Intelligent Learning Space in Open Universities Based on Room networking -- Taking the Construction and Application of "5g Room Networking Laboratory" of Fujian Radio and Television University as an Example. Modern Education Technology, 31(6):64-71. Yang, Y.P., Ding, G.M., \& Chen, Z.H. (2021). Design and Practice of Intelligent Learning Space in Open Universities. China Distance Education, 2021(9):39-48. DOI: https://doi.org/10.13541/j.cnki.chinade.2021. $\underline{09.005}$ 